\title{
Horas extraordinárias
}

Overtime

\author{
Marcos AurÉLIo Frantz Vianna \\ LUÍS ALFREDo COSTA
}

\section{RESUMO}

O presente estudo faz uma análise do direito material e processual ligada à percepção de horas extraordinárias, bem como tenta demonstrar as hipóteses de sua ocorrência, ou de vedação à jornada extraordinária. Aborda-se o Projeto de Lei do Senado no 224/2013 que regulamenta o trabalho do empregado doméstico, com ênfase no sistema de compensação de jornada de horas disposto no referido projeto.

Palavras-chave: Horas extras. Vedação à jornada extraordinária. Empregado doméstico.

\begin{abstract}
The present study is an analysis of substantive and procedural law linked to the perception of overtime, as well as attempts to demonstrate the chances of its occurrence, or sealing the extraordinary journey. Covers up the bill the Senate $\mathrm{n}^{\mathrm{o}}$ 224/2013 which regulates the work of domestic workers, with emphasis on compensation provisions hour journey system in this project.
\end{abstract}

Keywords: Overtime. Sealing the extraordinary journey. Domestic servant.

\section{INTRODUÇÃO}

A limitação da duração do trabalho foi sem sombra de dúvida a primeira reivindicação dos trabalhadores pós-revolução industrial, dada as massacrantes jornadas impostas pelos proprietários dos bens de capital da época. Conhecedor dos atritos provocados pela discussão acerca da duração do trabalho, e, inspirado pelo Tratado Versalhes que criou a Organização Internacional do Trabalho, o qual por sua vez propagou a necessidade de limitação da jornada em oito horas diárias, Getúlio Vargas editou diversos Decretos Lei estipulando o limite de jornada para diversas categorias profissionais, as quais posteriormente foram adensadas na novíssima Consolidação das Leis do Trabalho.
Com base nos regramentos contidos na Consolidação das Leis do Trabalho e na Constituição Federal de 1988, que reduziu a carga horária semanal de quarenta e oito horas para quarenta e quatro, o presente estudo abordará as diversas hipóteses de ocorrência de jornada extraordinária, ou, de impossibilidade de labor extra.

Outro ponto importante sobre horas extraordinárias reside no Projeto de Lei do Senado no 224/2013, aprovado pela casa legislativa e atualmente aguardando votação pela Câmara dos Deputados. O PLS no 224/2013 dispôs sobre a duração do trabalho do doméstico e introduziu curioso sistema de compensação de jornada extraordinária e, se assim prevalecer na Câmara dos Deputados, dificilmente será operacionalizado em âmbito doméstico.

\footnotetext{
a Advogado. Bacharel em Ciências Jurídicas e Sociais pela Pontifícia Universidade Católica do Rio Grande do Sul (PUCRS). Especialista em Direito e Processo do Trabalho pela PUCRS.<frantz@cpovo.net>.

b Advogado. Bacharel em Ciências Jurídicas e Sociais pela Universidade do Vale do Rio dos Sinos (UNISINOS). Pós-Graduado em Direito do Trabalho pela Universidade do Vale do Rio dos Sinos (UNISINOS). Pós-Graduado em Direito Previdenciário pela Escola Superior da Magistratura Federal, vinculado a Universidade de Caxias do Sul (UCS).<luis.costa@nsc.adv.br>.
} 


\section{MARCO CONSTITUCIONAL E LEGAL DE LIMITAÇÃO DE JORNADA E CARGA HORÁRIA SEMANAL}

A regulação da jornada de trabalho no Brasil espelhou-se nas lutas dos trabalhadores europeus e norte-americanos do período pós-revolução industrial, principalmente nas diretrizes do Tratado de Versalhes (1919) que instituiu a Organização Internacional do Trabalho.

Sobre a limitação da duração do trabalho, promulgou o Tratado de Versalhes em seu artigo 427 a necessidade de limitação da jornada de trabalho em 08 (oito) horas, o que permitiria o trabalhador descansar e participar do convívio familiar.

Ciente da necessidade de evitar o conflito entre o capital e o trabalho, e, assim poder desenvolver industrialmente o Brasil de forma mais célere, Getúlio Vargas dotou o ordenamento jurídico com medidas alinhadas com o Tratado de Versalhes concernente à limitação da jornada de trabalho ${ }^{1}$, tais como: Decreto 21.186 de 22 de março de 1932, que regulou o horário para trabalho no comércio; o Decreto 22.033 de 29 de outubro 1932, que alterou e aperfeiçoou o precedente; o Decreto 21.364, de 4 de maio de 1932, que regulou o trabalho industrial; o Decreto 22.979, de 24 de julho de 1933 que regulou a duração e condições de trabalho dos profissionais empregados em barbearias e estabelecimentos congêneres; o Decreto 23.152, de 15 de setembro de 1933, que regulou a duração do trabalho dos empregados em casa de diversões e estabelecimentos conexos; o Decreto 23.316, de 31 de outubro de 1933, que regulou a duração do trabalho dos empregados em casa de penhores e congêneres;

A unificação do sistema de duração do trabalho somente ocorreu em 1940, com o advento do DecretoLei $\mathrm{n}^{\mathrm{O}}$ 2.308, de 13 de junho de 1940, devendo ser respeitadas, todavia as exceções já disciplinadas nas leis anteriores.

Em 5 de novembro de 1942, a então comissão designada para elaborar a Consolidação das Leis de Proteção ao Trabalho fez um relatório concluindo os estudos do anteprojeto da mesma. Os membros responsáveis pela elaboração da exposição de motivos do referido projeto, apresentando em 1943. Faziam parte da presente comissão: Luiz Augusto de Rego Monteiro; José de Segadas Vianna; Arnaldo Lopes Sussekind; Dorival de Lacerda.

No trabalho dessa comissão que elaborou o projeto da Consolidação das Leis do Trabalho é que nasce a redação dos artigos 57 e 58, onde restou disciplinado que o regime de 8 horas deveria ser aplicado a todas as atividades de trabalho presentes no Brasil, salvo as expressamente excluídas, relativamente às peculiaridades especiais de algumas profissões ${ }^{2}$.

Nas Constituições de 1946 e de 1967 e não diferente na Emenda Constitucional no 1 de 1969, ficaram estabelecidos as limitações das jornadas não superiores a 8 horas diárias podendo serem reduzidas de comum acordo. Entretanto, a sua prorrogação só poderia ocorrer nos casos previstos em 1 li ${ }^{3}$.

Mais tarde, a partir da Constituição Federal de 1988, a jornada de trabalho sofreu novas alterações com a redação do artigo 7o- inciso XIII, o qual determinou expressamente limitação da jornada de trabalho e carga horária semanal em 08 horas diárias e 44 horas semanais, in verbis:

Art. 7 - São direitos dos trabalhadores urbanos e rurais, além de outros que visem à melhoria de sua condição social:

(...)

XIII - duração do trabalho normal não superior a oito horas diárias e quarenta e quatro semanais, facultada a compensação de horários e a redução da jornada, mediante acordo ou convenção coletiva de trabalho;

XVI - remuneração do serviço extraordinário superior, no mínimo, em cinqüenta por cento à do normal.

Considerando que a previsão semanal anterior era de uma jornada de 48 horas, houve um pequeno passo visando a redução das horas trabalhadas, mas, todavia, o legislador deve estar atento ao equilíbrio econômico entre o capital e o trabalho.

O favorecimento desmesurado do trabalho em detrimento do capital poderia acarretar a fuga de investimentos e aumento do preço dos produtos, acarretando graves prejuízos aos próprios trabalhadores. Por outro lado, o favorecimento do capital sem contrapartidas ao trabalho já é conhecido de todos nós por intermédio da revolução industrial e, nos dias de hoje, praticado pela China.

\section{DEFINIÇÃO DE JORNADA EXTRAORDINÁRIA}

A doutrina assenta a definição da jornada extraordinária a partir do seu elemento constitutivo preponderante tempo, o qual será contabilizada a partir do término da jornada normal de trabalho.

Nessa toada, Maurício Godinho Delgado define a jornada extraordinária como o 
lapso temporal de trabalho ou disponibilidade do empregado perante o empregador que ultrapasse a jornada padrão, fixada em regra jurídica ou por cláusula contratual. É a jornada cumprida em estrapolação à jornada padrão à relação empregaticia concreta.

A noção de jornada extraordinária não se estabelece em função da remuneração suplementar à do trabalho normal (isto é, pelo pagamento do adicional de horas extras). Estabelece em face $d a$ ultrapassagem da fronteira normal da jornad ${ }^{4}$.

Por sua vez, Carmem Camino caracteriza a jornada extraordinária como

[...] aquelas excedentes do limite máximo previsto para dia de trabalho. A carga horária semanal é a soma das jornadas. Se houver excesso de horas em algum ou alguns dias da semana, nem sempre haverá excesso de carga horária semanal, pois em outros dias o empregado poderá trabalhar menos do que os demais. ${ }^{5}$

Assim, o próprio sentido do termo "jornada extraordinária" bem identifica que a sobrejornada deve(ria) ocorrer somente em situações excepcionais, tal como disposto no artigo 61 da Consolidação das Leis do Trabalho.

No entanto, e, conforme melhor será visto adiante, o exercício da jornada extraordinária se ordinarizou com a implementação do sistema de "banco de horas" disciplinado pelo $\S 2^{\circ}$ do artigo 59 da CLT, situação essa teratológica a medida que a Constituição Federal define expressamente o limite da jornada e carga honorária semanal devidos pelo trabalhador (art. 7응 inciso XIII, CF).

\section{JORNADA COMPENSATÓRIA}

Na lição de Carmem Camino, o denominado "banco de horas" somente será válido quando respeitado o limite de 10 (dez) horas diárias de jornada. Segundo a referida autora, o empregado acumula uma espécie de crédito de horas suplementares de no máximo 02 (duas) horas por jornada, para futura compensação, mediante a correspondente diminuição ou supressão de jornadas, dentro de um período de um ano ${ }^{6}$.

Para tanto, nos termos do art. 59, $\S 2^{\circ}$ da $\mathrm{CLT}^{7}$ c/c artigo 7으. inc. XIII, CF, necessário prévio acordo ou convenção coletiva de trabalho que estabeleça a possibilidade do sistema de compensação.

Sobre a validade do sistema de compensação de horas, a Professora Carmem Camino aponta que somente pode ser computada como hora apta à compensação àquelas não excedentes ao limite de 10 (dez) horas diárias, devendo o excedente ser pago como extraordinárias, porque não podem ser compensadas. A compensação também está limitada ao teto da soma das "jornadas" semanais previstas para o período de um ano ${ }^{8}$.

Caso ocorra rescisão deverá ser pago as horas remanescentes nos termos do $\S 3^{\circ}$ do art. 59 CLT 9 .

\section{JORNADA EXTRAORDINÁRIA NO SITEMA LABORAL}

\subsection{Tratamento legal e definição}

A jornada extraordinária, como sua própria denominação sugere, é excepcional, vinculada à ocorrência de necessidade imperiosa (art. 61 da CLT). Portanto, as horas extras são de natureza circunstancial, vinculadas a determinados eventos que a lei enuncia taxativamente: a) força maior; b) necessidade imperiosa, quando diante da realização ou conclusão de serviços inadiáveis ou cuja inexecução possa acarretar prejuízo manifesto para o empregador"10.

Em verdade, as disposições restritivas do art. 61 estão praticamente ab-rogadas. A praxe das relações de trabalho tem consagrado o procedimento, notoriamente contra legem, das horas extras habituais. Conciliou-se o inconciliável, eis que o que é, por natureza, extraordinário, não pode ser habitual. A existência de horas extras habituais, ainda que pagas, até com adicionais superiores ao previsto na lei, configura, em verdade, abuso do direito de exigir trabalho, praticado pelo empregador. $[\ldots]^{11}$

Segundo a autora, a jurisprudência abrigou o entendimento de que havendo prestação de trabalho extraordinário habitual, durante mais de dois anos ou desde o início do curso do contrato, tais horas poderiam ser incorporadas à remuneração do trabalhador, conforme Súmula 76 do TST. No entanto, o TST mudou seu entendimento, admitindo apenas uma indenização em favor do empregado, conforme disposto na Súmula 291:

A prática de horas extras habituais está tão arraigada nas relações de trabalho que o próprio legislador as assimilou, ao determinar sua integração no cálculo do repouso semanal remunerado (art. 7º, alínea a, da Lei $n^{\circ} 605 / 49$, com a redação dada da Lei no 7.415/85)". Direito individual do trabalho, 3. ed. Porto Alegre: Síntese, 2003, p. 436. 


\subsection{Horas extras resultantes da não observância dos intervalos}

Além da conhecida possibilidade de percepção de horas extras por extrapolamento da jornada e carga horária semanal, ao trabalhador é devido como horas extras, com o respectivo adicional, labor em horários definidos pelo legislador como de repouso. Nesse sentido, passa-se analisar os vários tipos de intervalo devidos ao trabalhador e as consequências de sua não fruição.

\subsubsection{Intervalo Intrajornada}

Se o trabalhador tiver uma jornada de trabalho de oito horas contínuas sem intervalo a consequência é de uma hora considerada como extraordinária. Portanto o trabalhador terá direito a um adicional de $50 \%$ sobre uma hora pela não observância do intervalo, conforme inteligência da Súmula no 437 do TST.

Se o trabalhador laborar em uma jornada de trabalho de nove horas contínuas sem intervalo, ao trabalhador será devido o pagamento como hora extraordinária, acrescido do adicional de $50 \%$ (cinquenta por cento) referente ao período de repouso e alimentação. Será devido, ainda, o pagamento de uma hora extraordinária, com o respectivo adicional, concernente a hora excedente à oitava diária.

Isso está definido na regra geral do artigo 71 da CLT:

Art. 71. Em qualquer trabalho contínuo, cuja duração exceda de 6 (seis) horas, é obrigatória a concessão de um intervalo para repouso ou alimentação, o qual será, no mínimo, de 1 (uma) hora e, salvo acordo escrito ou contrato coletivo em contrário, não poderá exceder de 2 (duas) horas.

Pacificando a jurisprudência sobre o tema, o Tribunal Superior do Trabalho editou a Súmula no 437 . Verbis:

INTERVALO INTRAJORNADA PARA REPOUSO E ALIMENTAÇÃO. APLICAÇÃO DO art.71 DA CLT (conversão das Orientações Jurisprudenciais $\mathrm{n}^{\mathrm{Os}} 307,342,354,380$ e 381 da SBDI-1) - Res. 185/2012, DEJT divulgado em 25, 26 e 27.09.2012.

I - Após a edição da Lei no ${ }^{8.923 / 94}$, a nãoconcessão ou a concessão parcial do intervalo intrajornada mínimo, para repouso e alimentação, a empregados urbanos e rurais, implica o pagamento total do período correspondente, e não apenas daquele suprimido, com acréscimo de, no mínimo, 50\% sobre o valor da remuneração da hora normal de trabalho (art. 71 da CLT), sem prejuízo do cômputo da efetiva jornada de labor para efeito de remuneração.

II -É inválida cláusula de acordo ou convenção coletiva de trabalho contemplando a supressão ou redução do intervalo intrajornada porque este constitui medida de higiene, saúde e segurança do trabalho, garantido por norma de ordem pública (art. 71 da CLT e art. $7^{\circ}$, XXII, da CF/1988), infenso à negociação coletiva.

III - Possui natureza salarial a parcela prevista no art. $71, \S 4^{\circ}$, da CLT, com redação introduzida pela Lei no 8.923, de 27 de julho de 1994, quando não concedido ou reduzido pelo empregador o intervalo mínimo intrajornada para repouso e alimentação, repercutindo, assim, no cálculo de outras parcelas salariais.

IV - Ultrapassada habitualmente a jornada de seis horas de trabalho, é devido o gozo do intervalo intrajornada mínimo de uma hora, obrigando o empregador a remunerar o período para descanso e alimentação não usufruído como extra, acrescido do respectivo adicional, na forma prevista no art. 71, caput e $\S 4^{\circ}$ da CLT.

Observe-se, por oportuno, que nos dois exemplos acima a remuneração do intervalo com o adicional de $50 \%$ corresponde ao equivalente à uma hora extraordinária terá caráter punitivo e, não apenas remuneratório. Isso está definido na regra geral do $\S 4^{\text {O }}$ do art. 71 da CLT combinado com a súmula 437 anteriormente citada:

§4 Quando o intervalo para repouso e alimentação, previsto neste artigo, não for concedido pelo empregador, este ficará obrigado a remunerar o período correspondente com um acréscimo de no mínimo 50\% (cinquenta por cento) sobre o valor da remuneração da hora normal de trabalho. (Incluído pela Lei $\mathrm{n}^{-} 8.923$, de 27.7.1994)

Em contrapartida a essa regra, parte da jurisprudência trabalhista, antes da consolidação do critério descrito na súmula 437 do TST, adotava o princípio da razoabilidade, determinando o pagamento apenas da parte não usufruída do intervalo intrajornada como hora extra, e não todo o tempo do intervalo mínimo previsto em lei. Afinal, em raciocínio diverso, poderia haver pagamento como hora extra até do tempo de intervalo no qual houve fruição de descanso. Essa parcela da jurisprudência repudiava a ideia de que o empregado que usufruiu de intervalo de 55 minutos, por exemplo, tivesse direito ao pagamento de uma hora extra pela não fruição do intervalo mínimo de 1 hora, ao invés de ter direito somente ao pagamento de 5 minutos como extra. 
Por fim, necessário registrar que a jurisprudência dominante considera inválida cláusula de acordo ou convenção coletiva de trabalho que previa a supressão ou a redução do intervalo intrajornada previsto no art. 71 da CLT (Orientação Jurisprudencial 342 da SDI-1/TST agora convertida na Súmula no 437 do TST), resultando no pagamento e horas extras.

\subsubsection{Intervalo especial intrajornada}

A concessão de intervalo especial intrajornada ocorre pela necessidade e circunstância diferenciada da atividade desenvolvida pelo trabalhador, tudo a fim de assegurar ao obreiro condições sadias de trabalho.

Dentre as atividades profissionais com previsão de concessão do intervalo especial intrajornada, pode-se citar os serviços permanentes de mecanografia (art. 72 da CLT - datilografia, escrituração, cálculo e, por analogia, digitação); motorista profissional (235-D, inciso I, da CLT); trabalhadores em serviços frigoríficos (art. 253, caput, da CLT); trabalhadores em minas de subsolo (art. 298 da CLT). A mulher, por sua vez, terá direito, durante a jornada de trabalho, a dois descansos especiais, de meia hora cada um, para amamentar o próprio filho, até que este complete 6 meses de idade (art. 396 da CLT).

Importante salientar que a fruição deste intervalo especial será computada na duração normal de trabalho efetivo, ou seja, não há suspensão do contrato de trabalho. Na hipótese de não fruição do descanso especial será devido ao obreiro o pagamento do período como hora extraordinária, com o respecitivo adicional, nos moldes do artigo 71 da CLT.

\subsubsection{Intervalo interjornada}

A CLT também prevê que deve haver um intervalo mínimo entre duas jornadas de trabalho conforme estabelecido no artigo 66 que é no mínimo de 11 horas:

Art. 66. Entre 2 (duas) jornadas de trabalho haverá um período mínimo de 11 (onze) horas consecutivas para descanso.

Orientação Jurisprudencial 355/TST-SDI-I. Jornada de trabalho. Intervalo interjornadas. Inobservância. Horas extras. Período pago como sobrejornada. CLT, art.66. Aplicação analógica do $\S 4^{\circ}$ do art. 71 da CLT. súmula 110/TST. - O desrespeito ao intervalo mínimo interjornadas previsto no art. 66 da CLT acarreta, por analogia, os mesmos efeitos previstos no $\S 4^{\circ}$ do art. 71 da CLT e na Súmula 110/TST, devendo-se pagar a integralidade das horas que foram subtraídas do intervalo, acrescidas do respectivo adicional.
A jurisprudência é maciça quanto ao direito do obreiro ao recebimento de horas extras por exercício de atividade após o encerramento da jornada de trabalho ${ }^{12}$. Nesse sentido colaciona-se ementa de julgado proferido pelo Tribunal Regional do Trabalho sob a questão em pauta:

INTERVALO ENTRE JORNADA. Devido o pagamento de horas extras decorrentes da inobservância do intervalo mínimo de 11 horas entre jornadas, previsto no art. $8^{\circ}$, da Lei no ${ }^{\circ}$ 9.719/88, e art. 66, da CLT, independente se o trabalho restou prestado ao mesmo tomador de serviço. (RO n.. 000059080.2011.5.04.0122, 9aㅡ Turma do TRT da $4^{\text {a }}$ Região, Rel. Desa. Maria Madalena Telesca. Julgado em 31.05.2012)

\subsubsection{Intervalo interjornada combinando com o Descanso Semanal Remunerado}

Se houver absorção dos intervalos descritos no artigo 66 de $11 \mathrm{~h}$ e o do art. 67 de 24h, ambos da CLT o resultado será o pagamento das horas faltantes para completar os repousos como hora extraordinário com o devido adicional.

Citamos uma jurisprudência do TRT4 para exemplificar e que examina bem a questão bem como represente bem a jurisprudência majoritária daquele tribunal:

INTERVALO ENTREJORNADAS. O desrespeito ao descanso de 35 horas consecutivas entre duas jornadas de trabalho, consoante artigos $66 \mathrm{e}$ 67 da CLT, acarreta os mesmos efeitos do artigo 71, §4을 da CLT, deterrminando o pagamento, como extras, das horas eventualmente subtraídas do intervalo. Nessa linha é o entendimento consolidado na Orientação Jurisprudencial 355 da SDI1 do TST, aplicado por analogia. (RO 000028733.2011.5.04.0812, 10 $0^{\mathrm{a}}$ Turma do TRT da 4⿳⺈冂䒑 Região, Rel. Desa. Denise Pacheco. Julgado em 25.04.2013)

A Súmula $\mathrm{n}^{\mathrm{o}} 110$ do TST está relacionada ao mesmo tema:

JORNADA DE TRABALHO. INTERVALO (mantida)-Res. 121/2003, DJ 19, 20 e 21.11.2003.

No regime de revezamento, as horas trabalhadas em seguida ao repouso semanal de 24 horas, com prejuízo do intervalo mínimo de 11 horas consecutivas para descanso entre jornadas, devem ser remuneradas como extraordinárias, inclusive com o respectivo adicional.

Regime de Revezamento - Jornada de Trabalho - Intervalo - Horas Trabalhadas em Seguida ao Repouso Semanal - Remuneração do Empregado. 
Bem como a OJ 355/TST-SDI-I:

JORNADA DE TRABALHO. INTERVALO INTERJORNADAS. INOBSERVÂNCIA. HORAS EXTRAS. PERÍODO PAGO COMO SOBREJORNADA. CLT, ART. 66. APLICAÇÃO ANALÓGICA DO $\S 4^{\circ}$ DO ART.71 DA CLT. SÚMULA 110/TST. O desrespeito ao intervalo mínimo interjornadas previsto no art. 66 da CLT acarreta, por analogia, os mesmos efeitos previstos no $\S 4^{\circ}$ do art. 71 da CLT e na Súmula 110/TST, devendo-se pagar a integralidade das horas que foram subtraídas do intervalo, acrescidas do respectivo adicional.

\subsection{Deferimento de horas extras aos homens na hipótese do artigo 384 da CLT}

O artigo 384 da CLT prevê que em caso de prorrogação do horário normal do trabalho da mulher, será obrigatório um descanso de 15 (quinze) minutos no mínimo, antes do início do período extraordinário do trabalho. A concessão deste intervalo especial excepcionalmente à mulher gerou intenso debate na doutrina e na jurisprudência, posto que, após a promulgação da Constituição Federal que conferiu direitos iguais ao homem e à mulher, tal exceção contida na CLT afrontaria o artigo 5ำ caput, da CF.

No entanto, a referida controvérsia quanto à recepção do artigo 384 da CLT frente ao artigo 5o, caput, da Constituição Federal de 1988 restou dirimido pelo Tribunal Superior do Trabalho, conforme bem demonstra no julgado do Tribunal Regional do Trabalho da 4⿳亠丷厂 Região sobre o assunto em destaque:

INTERVALO DO ART. 384 DA CLT. O intervalo previsto no art. 384 da CLT considera a inegável desigualdade física entre homens e mulheres, não distinguindo, contudo, entre a capacidade intelectual e jurídica entre ambos os sexos. Tanto que o incidente de inconstitucionalidade do artigo em questão restou elidido no âmbito do Pleno do Tribunal Superior do Trabalho, mediante o julgamento do RR-1.540/2005-046-12-00.5. Assim sendo, por analogia do parágrafo $4^{\circ}$ do artigo 71 da CLT, tem-se que são devidos de forma simples quinze minutos de intervalo do artigo 384 da CLT por dia de trabalho excedente à jornada de oito horas, acrescido do adicional de 50\%. (RO 0001379-74.2012.5.04.0371, 7 a Turma do TRT da 4⿳亠丷厂 Região, Rel. Juiz convocado Manuel Cid Jardon, julgado em 21/11/2013)

Outrossim, subsiste debate jurisprudencial quanto à aplicação do artigo 384 da CLT aos trabalhadores homens. $\mathrm{O}$ fundamento para a concessão do intervalo especial aos homens antes do início da jornada extraordinária fundamentar-se-ia no princípio da igualdade entre os sexos esculpido no artigo $5^{\circ}$, caput, da CF.

Em recente decisão prolatada pelo Tribunal Regional do Trabalho da 4⿳亠丷厂 Região, de lavra do Des. Dr. Marcelo José Ferlin D Ambroso, analisou-se a questão à luz da Constituição Federal e da Convenção no 111 da OIT.

Ora, a regra não conflita com a Constituição Federal, ao estabelecer a igualdade entre homens e mulheres, pois, partindo-se dos conceitos orientativos da não discriminação da mulher e considerando o conceito aristotélico de igualdade, que consiste em tratar igualmente os iguais e desigualmente os desiguais, é de se entender por recepcionada a norma do art. 384 da CLT na Constituição da República, especialmente em face do disposto na Convenção 111 da OIT, cujo art.5, itens 1 e 2, dispõe que 'as medidas especiais de proteção ou de assistência previstas em outras convenções ou recomendações adotadas pela Conferência Internacional do Trabalho não são consideradas como discriminação' $\mathrm{e}$ 'qualquer Membro pode, depois de consultadas as organizações representativas de empregadores $e$ trabalhadores, quando estas existam, definir como não discriminatórias quaisquer outras medidas especiais que tenham por fim salvaguardar as necessidades particulares de pessoas em relação às quais a atribuição de uma proteção ou assistência especial seja, de uma maneira geral, reconhecida como necessária, por motivos tais como o sexo, a invalidez, os encargos de família ou o nível social ou cultural'.

O julgado restou assim ementado:

INTERVALO DO art. 384 DA CLT. HOMEM. Reconhecer a aplicação do intervalo do art. 384 da CLT para homens, que constitui norma de proteção especial ao trabalho da mulher, operaria em afronta aos preceitos das Convenções da OIT ratificadas pelo Brasil e que admitem a utilização de discriminações positivas como medidas especiais para salvaguarda de necessidades próprias das diferenças entre os sexos e em relação à nivelação do trabalho da mulher, em termos de mercado de trabalho, ao masculino. Recurso negado, no tópico. (RO 000123-38.2012.5. 04.0261, 1ํㅡ Turma do TRT da 4aㅡ Região, Rel. Des. Marcelo José Ferlin D Ambroso, julgado em 16/10/2013)

Em nosso sentir, a conferência do intervalo especial destinado à mulher também ao homem subsiste 
com fundamento na proteção à saúde do trabalhador frente ao desgaste natural do exercício da jornada extraordinária.

\subsection{Horas extras no período noturno e seus adicionais}

Definido pelo artigo 73 da CLT como o período compreendido entre 22 horas de um dia e as 5 h do dia seguinte para os trabalhadores urbanos, a hora noturna é fictamente menor que a diurna, correspondente a 52 minutos e 30 segundos de uma hora normal. Dispõe o artigo consolidado, ainda, que hora reduzida deverá obrigatoriamente ter um acréscimo de no mínimo $20 \%$ a mais do que a hora diurna.

$\mathrm{Na}$ hipótese de prorrogação da jornada em período considerado noturno, o cálculo da hora extraordinária, como respectivo adicional, deverá incidir sobre o valor da hora normal acrescido do adicional de $20 \%$ por exercício em labor noturno.

No entanto, em análise a julgados proferidos pelo Tribunal Regional do Trabalho da 4⿳亠丷厂 Região $^{13}$, as empresas reclamadas defendem que o cálculo a ser realizado para apuração do valor da jornada extraordinária em período noturno consiste na soma do adicional de $20 \%$ com o adicional de $50 \%$ da hora extra realizada, sob pena de cometimento de bis in idem em desfavor da reclamada e enriquecimento ilícito pelo trabalhador.

Espancando qualquer dúvida quanto à integração do adicional noturno na base de cálculo da jornada extraordinária, a Seção de Dissídios Individuais do TST editou a Orientação Jurisprudencial no 97 com o seguinte enunciado:

HORAS EXTRAS. ADICIONAL NOTURNO. BASE DE CÁLCULO. O adicional noturno integra a base de cálculo das horas extras prestadas no período noturno.

\section{RESTRIÇÕES À JORNADA EXTRAORDINÁRIA}

Motivada por questões econômicas e de proteção à saúde do trabalhador, em especial o trabalhador menor, definiu o legislador hipóteses de vedação ao exercício da jornada extraordinária, como a seguir a passa-se a analisar.

\subsection{Jornada tempo parcial}

A disciplina da jornada de tempo parcial inserida em nossa legislação trabalhista por meio da Medida Provisória n. ${ }^{-}$2.164-41, de 24 de agosto de 2001, que determinou a inserção do artigo 58-A na Consolidação das Leis do Trabalho, dispõe que a carga horária semanal do trabalhador contratado para este regime de trabalho será de no máximo 25 horas semanais.

Por sua natureza especial, que em tese propiciaria aumento na contratação de trabalhadores, o legislador definiu taxativamente no $\S 4^{\mathrm{O}}$ do artigo $59^{14}$ que os empregados contratados por esse regime não poderão prestar horas extras.

A realização de jornada extraordinária na hipótese de contratato por tempo parcial resultaria na desqualificação total do regime, em todos seus aspectos essenciais definidos nos artigos 130-A, §3ํㅡㄹ do artigo 143, fazendo incidir o regramento geral disposto na CLT.

Outro aspecto importante do regime de tempo parcial reside no fato de que o caput do artigo 58-A da CLT dispõe apenas sobre o limite da carga horária semanal, nada tratando sobre a duração diária do trabalho. No entendimento de Maurício Godinho Delgado "isso significa que um contrato de tempo parcial à base de 24 horas semanais pode ser cumprido seja através de jornadas de quatro horas (durante seis dias na semana), como também através de jornadas mais amplas, de oito horas por exemplo, (laborando-se, em consequência, somente três dias ao longo de toda a semana) ${ }^{15}$.

Mesmo tratando-se de modalidade excepcional de contratação, a duração diária de trabalho não pode ser superior àquela definida pelo artigo art. 7º , inciso XIII, da Constituição Federal.

\subsection{Atividades insalubres}

Nos exatos termos do artigo 60 da CLT, a prorrogação da jornada somente poderá ocorrer mediante prévia licença das autoridades competentes em matéria de higiene do trabalho.

Em que não pairar dúvida quanto ao sentido do enunciado contido na norma em questão, o Tribunal do Superior do Trabalho possuía entendimento consolidado na Súmula 349 de que em havendo disposição em convenção coletiva de trabalho, a sobrejornada em atividade insalubre prescindiria de prévia inspeção de autoridade competente em matéria de higiene do trabalho.

A razão de ser da Súmula 349 do TST resultava do entendimento daquele Sodalício de que o artigo 60 da CLT não havia sido recepcionado pelo artigo 7º, inciso XIII da Constituição Federal, a qual prevê a possibilidade de compensação de jornada mediante acordo ou convenção coletiva. Por ser expressão da vontade das partes contratantes, a norma coletiva poderia desprezar normas de saúde pública, como àquela disposta no artigo $60 \mathrm{da} \mathrm{CLT}^{16}$. 
No entanto, com o aprimoramento do entendimento jurisprudencial sobre a importância de manutenção de normas protetivas à saúde e segurança do trabalhador, o Tribunal Superior do Trabalho cancelou em 2011 a Súmula 349, reavivando a norma do artigo 60 da Lei Laboral.

Dada a importância do debate sobre a necessidade de inspeção prévia pelo agente público encarregado em higiene e segurança do trabalho, pede-se vênia para trazer à lume as palavras de Maurício Godinho acerca do tema:

A respeito desse tópico, sempre insistimos que não havia qualquer incompatibilidade entre o texto constitucional vigorante e a exigência celetista de vistoria administrativa prévia para pactuação de sobrejornada ou compensação de honorários em situações laborais insalubres. É que uma larga multiplicidade de normas constitucionais coloca a saúde e segurança do obreiro em patamar destacado e superior a interesses protegidos por outras normas jurídicas, inclusive trabalhistas (ilustrativamente, arts. 7º, XXII; 194; 196; 197; 200, II, CF/88). Pelo Texto Magno, a saúde e segurança laborais são direito subjetivo obreiro, constituindo, ainda, parte integrante e exponencial de uma política de saúde pública no país. Não há, ao revés, na Constituição qualquer indicativo jurídico de qualquer processo negocial coletivo. $\mathrm{Na}$ verdade, está-se aqui diante de uma das mais significativas limitações manifestadas pelo princípio da adequação setorial negociada, informador de que a margem aberta às normas coletivas negociadas não podem ultrapassar o patamar sociojurídico civilizatório característico das sociedades ocidental e brasileira atuais. Nesse patamar, evidentemente, encontra-se a saúde pública e suas repercussões no âmbito empregatício. $^{17}$

A guisa de ilustração colaciona-se a seguinte emenda proveniente de Acórdão do TST:

RECURSO DE REVISTA. HORAS EXTRAS. ACORDO INDIVIDUAL DE COMPENSAÇÃO. ATIVIDADE INSALUBRE. Com o cancelamento da Súmula no 349 desta Corte, evidenciou-se a necessidade de autorização do Ministério do Trabalho e Emprego para a celebração de acordo de compensação de jornada em atividade insalubre, nos termos do art. 60 da CLT.

Precedentes. Recurso de revista conhecido e provido. (RR 1377-51.2010.5.12.0016, Data de julgamento: 16/05/2012, Relatora Ministra Dora Maria da Costa, 8 ${ }^{\mathrm{a}}$ Turma do TST, data de publicação no DEJT 17/05/2012)

\subsection{Restrição à jornada extraordinária do Menor}

A Consolidação das Leis do Trabalho elenca em seu artigo 413, caput, vedação à jornada extraordinária do trabalhador menor $^{18}$. No entanto, os parágrafos $1^{\mathrm{o}}$ e $2^{\circ}$ do citado artigo possibilitam o prolongamento da jornada do menor nas hipóteses de regime de compensação ou de força maior.

Tratando-se de trabalhador menor, não há que falar em possibilidade de prorrogação da jornada extraordinária em atividade insalubre após a realização de perícia por autoridade administrativa responsável pela higiene e segurança do trabalhador (artigo 60 da CLT). O artigo 7º , inciso XXIII, da Constituição Federal, veda terminantemente a contração de trabalhador menor para o exercício de atividade insalubre, perigoso ou noturno, sendo impassível de aplicação nestes casos a permissão de prorrogação de jornada disposta nos parágrafos $1^{\circ}$ e $2^{\circ}$ do artigo 413 da CLT.

\section{JORNADA EXTRAORDINÁRIA DO EMPREGADO DOMÉSTICO}

Com o advento da Constituição Federal de 1988 os direitos sociais dos trabalhadores foram elevados à categoria de direitos fundamentais (art. 7oㅡ, CF/88), fato esse demonstrativo da importância e preocupação do legislador constituinte originário de garantir aos trabalhadores a proteção não apenas legal, mas constitucional desses direitos sociais.

No entanto, o próprio legislador constituinte que inseriu no texto constitucional plêiade de direitos elencados no artigo $7^{\circ}$ da Constituição Federal, fez constar no $\S$ único do artigo $7^{\circ}$ que os trabalhadores domésticos seriam contemplados apenas com parte daqueles direitos sociais, excluindo, por exemplo, limite na duração da jornada de trabalho e pagamento de adicional de 50\% (cinquenta por cento) decorrente da jornada extraordinária.

Críticas à segregação realizada à época pelo Legislador Constituinte Originário, o Congresso Nacional promulgou a Emenda Constitucional $\mathrm{n}^{\mathrm{0}}$ 72, de 2 de abril de 2013, que conferiu à categoria dos empregados domésticos os mesmos direitos sociais devidos aos trabalhadores brasileiros.

Saudada pela sociedade civil o notável e histórico resgaste dos trabalhadores domésticos promovido pelo Congresso Nacional por meio da EC no 72/2013, a alteração constitucional pende de regulação a ser provida por Lei, especialmente em relação a questões tributárias e de controle da jornada de trabalho. 
Nesse sentido, o Senado Federal elaborou o Projeto de Lei (PLS) no 224/2013, aprovado em julho de 2013 naquela casa legislativa e aguardando atualmente inclusão em pauta para que seja votada pela Câmara dos Deputados.

Concernente ao objeto da presente pesquisa (horas extras), o PLS no 224/2013 dispõe que a carga honorária semanal máxima de trabalho será de 220 (duzentos e vinte e duas) horas semanais e 08 (oito) horas diárias (art. 20, caput); adicional de 50\% (cinquenta) por cento sobre o valor normal da hora na hipótese de jornada extraordinária (art. $2^{\mathrm{o}}, \S 1^{\mathrm{o}}$ ); possibilidade de instauração de regime de compensação (artigos $2^{\underline{Q}}$, $\S \S 4^{\mathrm{o}}$ e $\left.5^{\mathrm{o}} ; 11\right)$;

Limitada a jornada e carga horária semanal do trabalhador doméstico a 08 (oito) horas diárias e 44 (quarenta e quatro) horas semanais, o Projeto de Lei do Senado n. ${ }^{\circ}$ 224/2013 estabeleceu curioso regime de pagamento e compensação de eventuais horas extraordinárias realizadas pelo trabalhador doméstico.

Mediante acordo escrito entre empregador e empregado doméstico, o trabalho extraordinário realizado ser compensado em outro dia, sem qualquer acréscimo de salário ( $\$ 4^{\circ}$ do artigo 2 ). Instituído o regime de compensação de horas extraordinárias, prevê o projeto de lei que as primeiras 40 (quarenta) horas extras mensais deverão ser pagas ao trabalhador, admitindo, entretanto, o abatimento do montante de horas em virtude de dias não trabalhados pelo empregado ou, na hipótese de redução da jornada de trabalho (incisos I e II, $\S 4^{\circ}$, artigo $2^{\circ}$ ).

Por sua vez, o inciso III do $\S 4^{\circ}$, artigo $2^{\circ}$ do Projeto de Lei prevê que o saldo de horas extras mensais superior a 40 (quarenta) horas deverão ser incluídas em banco de horas, devendo o trabalho ser compensado no período máximo de 01 (um) ano.

O curioso sistema de compensação estatuído pelo Projeto de Lei, caso aprovado, determinará a obrigatoriedade do pagamento de horas extras ao trabalhador, com o respectivo adicional, até o limite de quarenta horas extras por mês, resultando, na prática, no esvaziamento do regime de compensação de horas.

Ora, não é difícil imaginar que o empregador doméstico deverá ser severo com o cumprimento da jornada de trabalho pactuada, visto que obrigatoriamente terá que pagar horas extraordinárias ao trabalhador, mesmo após a instituição do regime de compensação.

\section{CONCLUSÃO}

Pode-se inferir do presente estudo que a jornada extraordinária ordinarizou-se, motivado em grande parte pela larga flexibilidade do sistema do banco de horas, e, sem embargo de dúvida, pelo trabalhador que vê na jornada extraordinária uma possibilidade de aumento de sua remuneração.

Nesse sentido, a releitura dos dispositivos constitucionais e legais acerca da matéria é imprescindível para o aprimoramento das relações do trabalho, com ênfase especial à saúde e segurança do trabalhador.

Por último, quanto ao empregado doméstico, impõese como necessário aprimoramento do Projeto de Lei do Senado no 223/2013 quanto ao regime de compensação de horas, pois, se aprovado pelo Congresso Nacional e sancionado pela Presidência da República no estado em que encontra, trará ao empregador doméstico sérias dificuldades de manutenção do empregado, o que poderia maximizar a redução de postos de trabalho no setor.

\section{REFERENCIAS}

BEZERRA LEITE, Carlos Henrique. Registro Eletrônico de Ponto e o Ônus da Prova - A Nova Portaria do MTE sobre Registro Eletrônico de Ponto e a questão da Inversão do Ônus da Prova. Revista IOB Trabalhista e Previdenciária, ano XXI, n. 247, jan. 2010.

CAMINO, Carmen. Direito individual do trabalho. 3. ed. Porto Alegre: Síntese, 2003.

DELGADO, Maurício Godinho. Curso do Direito do Trabalho. 12. ed. São Paulo: LTr, 2013.

LIMA, Claudia Rejane de. IV.2 Hora Extra e Saúde no Contexto da Produção Enxuta, CUT. Hora Extra: o que a CUT tem a dizer sobre isto. Secretaria de Política Sindical da CUT Brasil. São Paulo: CUT Brasil, 2006.

MARTINS, Sergio Pinto. Ônus da Prova no Processo do Trabalho - Ônus da Prova Relativo no Processo do Trabalho. Revista IOB Trabalhista e Previdenciária, ano XVII, n. 202, abr. 2006.

MASCARO NASCIMENTO, Sônia Aparecida Costa. Flexibilização do horário de trabalho. São Paulo: LTr, 2002.

SCHWARZ, Rodrigo Garcia. Ônus da Prova no Processo do Trabalho - Breves considerações sobre as Regras de Distribuição do Ônus da Prova no Processo do Trabalho. Revista IOB Trabalhista e Previdenciária, ano XVII, n. 202, abr. 2006.

SUSSEKIND, Arnaldo. Direito Brasileiro do Trabalho. Rio de Janeiro: "A Noite"/Livraria Jacinto, 1943. Vol. I.

\section{NOTAS}

1 SUSSEKIND, Arnaldo. Direito Brasileiro do Trabalho. Vol. I. Rio de Janeiro: "A Noite"/Livraria Jacinto Ed., 1943, p. 191.

2 Ibidem, p. 193.

3 MASCARO NASCIMENTO, Sônia Aparecida Costa. Flexibilização do Horário de Trabalho. São Paulo: LTr, 2002, p. 29.
4 DELGAdo, Maurício Godinho. Curso do Direito do Trabalho. 12. ed. São Paulo: LTr, 2013, p. 936.

5 CAMINO, Carmen. Direito individual do trabalho. 3. ed. Porto Alegre: Síntese, 2003, p. 428.

6 Ibidem, p. 431.

Art. 59. A duração normal do trabalho poderá ser acrescida de horas suplementares, em número não excedente de 2 (duas), mediante acordo 
escrito entre empregador e empregado, ou mediante contrato coletivo de trabalho. $\$ 2$-Poderá ser dispensado o acréscimo de salário se, por força de acordo ou convenção coletiva de trabalho, o excesso de horas em um dia for compensado pela correspondente diminuição em outro dia, de maneira que não exceda, no período máximo de um ano, à soma das jornadas semanais de trabalho previstas, nem seja ultrapassado o limite máximo de dez horas diárias.

8 CAMINO, Carmen. Direito individual do trabalho. 3. ed. Porto Alegre: Síntese, 2003, p. 432.

$9 \S 3^{\mathrm{o}} \mathrm{Na}$ hipótese de rescisão do contrato de trabalho sem que tenha havido a compensação integral da jornada extraordinária, na forma do parágrafo anterior, fará o trabalhador jus ao pagamento das horas extras não compensadas, calculadas sobre o valor da remuneração na data da rescisão. (Incluído pela Lei $n^{\circ}$ 9.601, de 21.1.1998).

$\S 4$ ㅇ-Os empregados sob o regime de tempo parcial não poderão prestar horas extras. (Incluído pela Medida Provisória no 2.164-41, de 2001).
${ }^{10}$ CAMINO, Carmen. Direito individual do trabalho, 3. ed. Porto Alegre: Síntese, 2003, p. 434

11 Ibidem, p. 435

12 PORTTUMATI, Eduardo Carlos. A caracterização de horas extras em face da inobservância dos intervalos legais. Revista LTr: Legislação do Trabalho, São Paulo, v. 62, n. 8, p. 1034-1041, 1998.

13 RO no 0000272-93.2011.5.04.0382, 7⿳亠丷厂 Turma do TRT da 4ª Região, Rel. Desa. Maria da Graça Ribeiro Centeno, julgado em 22 de agosto de 2013.

14 parágrafo acrescentado por força da Medida Provisória n 2.164-41, de 24 de agosto de 2001.

15 DELGADO, Maurício Godinho. Curso do Direito do Trabalho. 12. ed. São Paulo: LTr, 2013, p. 954

16 Ibidem, p. 913.

17 Ibidem, p. 913-914.

18 Nos termos do artigo 402 da CLT, considera-se menor o trabalhador de quatorze anos até dezoito anos.

Recebido em: 15/09/2014; aceito em: 07/10/2014. 